\title{
Spatio-temporal characteristics of intra-urban land cover in the cities of China and USA from 1978 to 2010
}

\author{
CHI Wenfeng ${ }^{1,2}$, SHI Wenjiao ${ }^{1},{ }^{*}$ KUANG Wenhui $^{1}$
}

1. Key Laboratory of Land Surface Pattern and Simulation, Institute of Geographic Sciences and Natural Resources Research, CAS, Beijing 100101, China;

2. University of Chinese Academy of Sciences, Beijing 100049, China

\begin{abstract}
Urban land cover has major impacts on a city's ecosystem services and the inherent quality of its urban residential environment. The spatio-temporal distribution of impervious surface area and green areas in Chinese cities has exhibited a significantly marked difference in comparison with USA cities. This study focused on monitoring and comparing the spatio-temporal dynamics, land cover patterns and characteristics of functional regions in six Chinese $(n=3)$ and USA $(n=3)$ cities. The study data were collated from Landsat TM/MSS imagery during the period 1978-2010. Results indicate that Chinese cities have developed compactly over the past three decades, while development has been notably dispersed among USA cities. Mean vegetation coverage in USA cities is approximately 2.2 times that found amongst Chinese urban agglomerations. Land use types within Chinese cities are significantly more complex, with a higher density of impervious surface area. Conversely, the central business district (CBD) and residential areas within USA cities were comprised of a lower proportion of impervious surface area and a higher proportion of green land. Results may be used to contribute to future urban planning and administration efforts in both China and the USA.
\end{abstract}

Keywords: urban structure; impervious surface area; vegetation; China; USA; remote sensing

\section{Introduction}

The extent of global migration from rural to urban areas has significantly increased, with the urban proportion of the global population reaching 51.6\% in 2010 (UNDESA, 2012a). Rapid urbanization and industrialization is ongoing in China due to policy reform and the relaxation of national and regional borders. The urban proportion of the Chinese population in-

Received: 2014-06-05 Accepted: 2014-08-15

Foundation: National Natural Science Foundation of China, No.41371408; National High-Tech R\&D Program of China, No.2013AA122802; National Basic Research Program of China, No.2010CB950900; No.2014CB954302; National Key Technology R\&D Program, No.2012BAJ15B02

Author: Chi Wenfeng, PhD, specialized in land use and cover change. E-mail: chiwenfeng2005@126.com

${ }^{*}$ Corresponding author: Kuang Wenhui (1978-), Associate Professor, specialized in land use and cover change (LUCC) and urban ecology and environment. E-mail: kuangwh1978@sina.com 
creased from $19.4 \%$ in 1980 to $49.2 \%$ in 2010 . This implies a $29.8 \%$ urban growth rate, which has been reportedly increased to greater than $50 \%$ by the end of 2012 . Comparatively, the urban population of the United States has increased from $73.7 \%$ to $82.1 \%$ during the same period (UNDESA, 2012a), thus representing an urban growth rate of $8.4 \%$. Thus, significant differences exist with respect to levels of urbanization and developmental patterns between China and the USA, which are considered developing and developed countries, respectively. Due to the continual migration of populations from rural to urban areas, the resulting metropolitan expansion and acceleration of global environmental change (e.g. increased ambient temperatures, increased flooding, frequent sand and extreme heat events), both urban ecosystems and the inhabitable environment are being confronted with unprecedented challenges (McGranahan et al., 2007; Grimm et al., 2008; Alberti et al., 2010; Grimmond et al., 2010; Seto et al., 2012). The structure and composition of intra-urban land cover, which includes both impervious surface areas (ISA) and green spaces, impact both surface radiation and energy distribution (Van et al., 2011). They can also affect the urban heat island effects, the atmospheric environment and local climate. Thus, intra-urban land cover plays a key role in the heat-regulating functions associated with ecosystem services (Oke et al., 1982; McGranahan et al., 2007; Grimm et al., 2008; Kuang et al., 2011; Goldbach et al., 2012; Laaidi et al., 2012). Urban ecosystem services have been found to directly affect both urban residential environments and societal welfare (MEA, 2003). Therefore, appropriate urban land planning is necessary for urban ecosystem service improvement, residential development, continued reduction of global carbon emissions and climate change adaptation. Consequently, the study of intra-urban land cover is particularly significant, both practically and theoretically, for evaluation of urban ecosystems and inhabitable environments. ISA and vegetation components are the most significant components of intra-urban land cover (Steve et al., 2012).

Urban ISA is a man-made land use type, classified by an absence of direct surface water infiltration and includes paved roadways, plazas, parking-lots and building roofs. It is considered as a significant indicator of anthropogenic intensity and urban development (Arnold et al., 1996; Lu et al., 2011). As an urban ecosystem component, urban green spaces play an important role in improving the urban environment. For example, they have been found to facilitate purification of both air and water, energy conservation, ambient temperature readjustment and ultraviolet light reduction (Wolf et al., 2003; Nowak et al., 2007; Byomkesh et al., 2012; Zhang et al., 2009). Furthermore, increased metropolitan green space proportions have been correlated with microclimate regulation, reduced urban surface temperatures and altered radiation energy balances (Yuan et al., 2007; Tong et al., 2005; Ashie et al., 1999). A previous study (Yue et al., 2006) has shown that 'forest cover' and green space play a pivotal role in the thermal regulation of ecosystem services. A $10 \%$ increase in the proportion of metropolitan green space is estimated to result in a $2^{\circ} \mathrm{C}$ thermal radiation reduction, with considerable reductions noted in concurrence with green spaces $>5 \mathrm{~km}^{2}$ (Ying et al., 2010). Monitory data via remote sensing indicate that the proportion of ISA associated with USA inner cities varies within a mean range of $40 \%-50 \%$, while this proportion is estimated to be approximately 66\% with respect to Chinese metropolitan regions (Nowak et al., 2012; Kuang et al., 2013). Based on an amalgamation of night lighting index (DMSP/OLS) and Chinese land use/cover change data, results suggest that increased ISA has been representative of high growth regions in China during the early 21st century, particularly in the urban 
areas of Beijing, Tianjin and Tangshan. Aerial imagery surveys have shown that the mean proportion of impervious coverage associated with USA cities during 2005 was 43\% (Nowak et al., 2012). During the 26-year period 1984-2010, the impervious area in Baltimore metropolitan area increased from $881 \mathrm{~km}^{2}$ to $1176 \mathrm{~km}^{2}$ (Sexton et al., 2013). Ambient temperatures in areas adjacent to urban parks are significantly lower than those associated with green spaces within these parks. Temperatures are decreased by $1.5^{\circ} \mathrm{C}$ for every 0.6 $\mathrm{km}^{2}$ of the park in a $1 \mathrm{~km}$ downwind radius of the business district. The cold island effect is increasingly marked in larger green areas; temperature differences of up to $3.5^{\circ} \mathrm{C}$ have been recorded between urban green areas with high levels of vegetation cover and adjacent urban areas (Cao et al., 2010). Temperature differences between green spaces and adjacent urban areas are typically elevated during summer months and reduced during winter months. The 'Icelandic' effect, which effectively reduces urban temperatures, may extend for up to 200-300 $\mathrm{m}$ at night in urban areas and > $500 \mathrm{~m}$ during summer months (Ying et al., 2010; Wang et al., 2007; Potchter et al., 2006). With respect to the intensity of urban heat islands and environmental quality, conditions in China and the USA differ significantly.

Accordingly, the two primary objectives of the current study were: i) to investigate differences pertaining to the structural characteristics of urban land cover in China and the USA during the past 30 years, and ii) to analyze the differences pertaining to the patterns and the structural features of ISA and green land in differing functional areas.

\section{Research methods}

The internal spatial structure of a city results from multiple interactions between its land cover types and functional areas. Urban land cover types are typically categorized as ISA, vegetation, water and others (made ground, bare soil, etc.). With reference to the type and inherent characteristics of functional areas, these are generally classified as commercial land, residential land, industrial land and others (e.g. commercial habitat mixed land) (Kuang et al., 2010). The development of a functional characteristic is based on the dual assumptions that land cover type may be extracted via remote sensing and that the dominant function associated with the delineated constraints may be observed and summarized (Eqn. 1).

$$
\begin{aligned}
& 1=\sum_{i=1}^{n} F_{n} L_{n} \\
& P C M=\frac{C_{L}+C_{G}+C_{W}+C_{O}}{n_{L}+n_{G}+n_{W}+n_{O}} \times 100 \% \\
& M R E=\frac{\sum_{i=1}^{n}\left(\left|x_{i}-y_{i}\right| / y_{i}\right)}{n}
\end{aligned}
$$

where 1 represents the internal structure of the city; $F_{n}$ represents the coefficient of functionality and $L_{n}$ represents the ratio of the structure of urban land cover type.

The theoretical model of urban location and internal land cover components is presented in Figure 1; as shown, the proportion of ISA is higher in areas closer to the city center, in concurrence with more increasingly concise land cover delineation. For example, the proportion of ISA within the central business district is large, while the proportion of other land cover types is small; higher proportions of impervious area are associated with urban resi- 
dential land, while industrial land is typically associated with increased proportions of green space or bare land, but decreased proportions of impervious area.

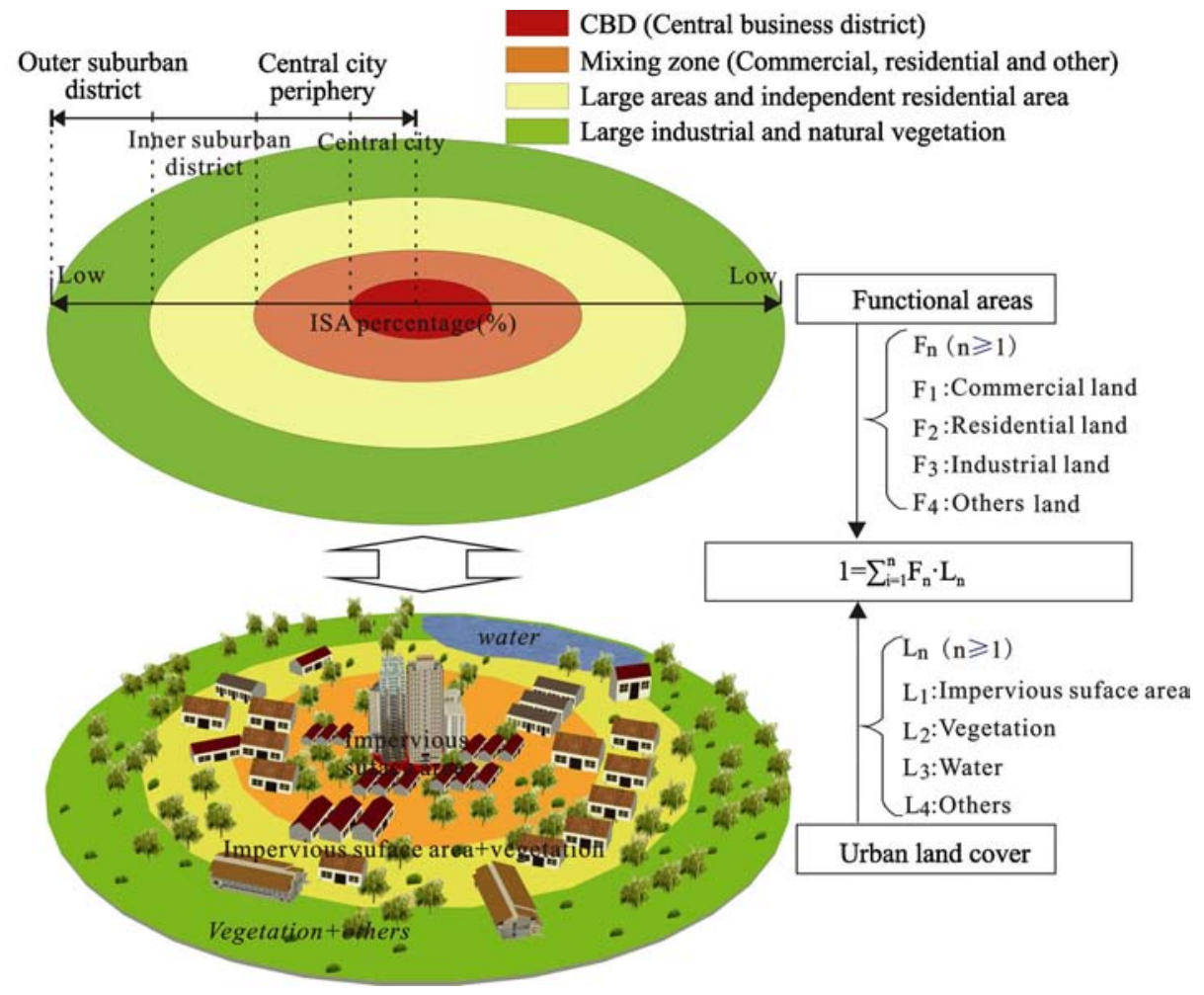

Figure 1 Theoretical model of urban locations and land cover components

\section{Study areas and datasets}

\subsection{Study areas}

Beijing, Shanghai and Guangzhou are the primary metropolitan regions of the Beijing-Tianjin-Hebei region, Yangtze River Delta and Pearl River Delta city group, respectively. Moreover, they represent the three most populated urban agglomerations in China. Beijing is the capital of the People's Republic of China and a globally renowned historical, cultural and economic center. The topography of Beijing is high in the northwest and low in the southeast, with a mean altitude of $43.5 \mathrm{~m}$. Beijing has a warm humid climate with a mean annual temperature of $13.4^{\circ} \mathrm{C}$ and a mean annual precipitation of $644.2 \mathrm{~mm}$. Shanghai is a famous port city, located in the Yangtze River delta plain at the hub of a concentrated network of waterways. The climate of Shanghai is a north subtropical monsoon climate with a mean annual temperature of $15.8^{\circ} \mathrm{C}$, an annual mean rainfall of $1123.7 \mathrm{~mm}$ and a mean altitude of $4 \mathrm{~m}$. Guangzhou as the capital of Guangdong Province, with topography descending from northeast to southwest. Its maritime climate is characterized by an annual mean temperature ranging from $21.5-22.2^{\circ} \mathrm{C}$ and mean annual precipitation $>1800 \mathrm{~mm}$.

New York, Chicago and Los Angeles are located on the Atlantic USA coast, the Great Lakes coast and the Pacific USA coast, respectively, and are the three most populous cities 
in the USA. New York City is the world's largest financial center and the country's third largest industrial center after Chicago and Los Angeles. It has a humid subtropical climate with mean annual temperature of $11^{\circ} \mathrm{C}$ and annual precipitation of $1091 \mathrm{~mm}$. Los Angeles is located in southern California and borders the San Pedro and Santa Monica Bays, on the eastern verge of the Pacific Ocean. It represents the primary American base for the petrochemical, marine, aerospace industry and electronics industries, in addition to being a major center of science and technology. The climate is categorically Mediterranean with an annual mean temperature of $12^{\circ} \mathrm{C}$ and an annual precipitation of $357 \mathrm{~mm}$. Chicago is located in northeast Illinois and is the world's most important financial center. Moreover, it comprises the second largest central business district and the most important railroad and aviation hub in the USA. Summarily, regional topography may be described as being flat, with an average altitude of $176 \mathrm{~m}$. It has a humid temperate continental climate with abundant rainfall (mean annual rainfall: $974 \mathrm{~mm}$ ) (Figure 2).

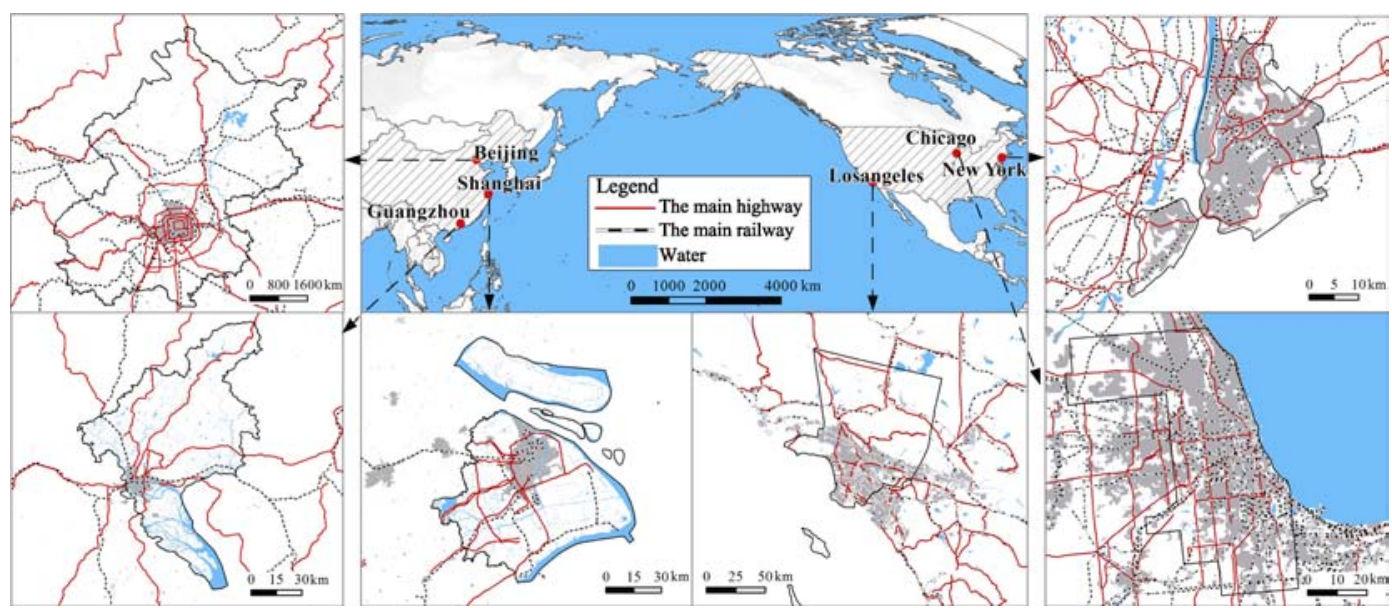

Figure 2 Locations of the study cities

\subsection{Datasets}

Remote sensing Landsat MSS images from 1978 and Landsat TM/ETM image from 1990, 2000 and 2010 were downloaded from the USA Geological Survey website (http://glovis.usgs.gov/). These were used to explore the evolutionary patterns of land cover structure and characteristics within diverse functional areas in six Chinese and USA cities (Section 3.1) over the past three decades. Images from similar seasons were selected from the latest two years of each data period, with images screened for resolution quality. Upon conversion to UTM projection format, each image underwent geometric correction according to imagery resolution from 2010, with a spatial error < one pixel employed (60 m in 1978, 30 m during other periods). Accordingly, radiation image Digital Number (DN) values were converted to satellite reflectance values.

Urban construction land was defined as non-agricultural land included for urban planning, including concentrated structures, adjacent inner city regions and other construction land associated with suburbs/urban fringe areas. Criteria for assessment of the urban/rural boundary were infrastructural completion and the degree of association with the city (Kuang et al., 2010). The urban land cover classification system comprises four land cover types, 
namely internal ISA, vegetation, water and other land. In order to effectively calculate the ISA and vegetation coverage proportion, a linear decomposition method for spectral mixed pixels was employed. Specific steps include image data dimensionality reduction, end-member extraction and post-processing. To reduce the impacts of the image band dimension, minimum noise fraction transformation was used. The first three principal components of values whose contribution rates are over $81.3 \%$ were selected to extract pure pixel end member information and to obtain meta-information pertaining to high albedo, low albedo, vegetation and bare soil. High and low albedo data may be used to represent ISA information. Water and vegetation information were obtained via use of the improved normalized water indices and normalized difference vegetation indices, respectively. Subsequently, urban land cover maps for the study years resulted from an effective amalgamation of the water and vegetation areas.

Based upon the urban construction land areas of the six cities in 2010, spatial information pertaining to urban land cover changes was obtained via spatial operations with extracted classification data from 2010. Images from Google Earth (2010) and aerial photography collected during other periods were used to verify the accuracy by contrasting the unchanged and changed areas during the study periods via a stratified random sampling method. Indicators such as classified Percent Correct Metric (PCM) and the Mean Relative Error (MRE) were used for accuracy assessment (Kuang et al., 2013). The mean accuracy rate of urban land cover classification is equal to the ratio of the number of samples correctly identified respectively from the four land cover types and the total number of samples from each land cover type (Eqn. 2):

$$
P C M=\frac{C_{L}+C_{G}+C_{W}+C_{O}}{n_{L}+n_{G}+n_{W}+n_{O}} \times 100 \%
$$

where $P C M$ is the accuracy rate of urban land cover classification, $C_{L}, C_{G}, C_{W}, C_{O}$ and $n_{L}, n_{G}$, $n_{W}$ and $n_{O}$ are the number of samples classified correctly and the total number of samples (ISA, vegetation, water, and other).

$M R E$ was used to evaluate the extraction accuracy of quantitative composition information pertaining to the proportion of ISA and green space in each (mixed) pixel (Eqn. 3):

$$
M R E=\frac{\sum_{i=1}^{n}\left(\left|x_{i}-y_{i}\right| / y_{i}\right)}{n}
$$

where MRE represents mean relative error; $x_{i}$ and $y_{i}$ represent the proportion of ISA and green space, respectively; ISA was calculated via interpreted information extracted from a $3 \times 3$ pixel of high-resolution remote sensing images (\%); $n$ is the number of samples.

In order to reduce the impact generated from image registration errors, a $3 \times 3(90 \mathrm{~m} \times 90$ m) window for each sampling point pixel was applied to obtain verification samples via expert manual interpretation of rectified high resolution imagery. In all, 130 samples were selected from each city. Impervious layer data were reclassified based on 10 pre-defined grades $(1-10,10-20, \ldots, 90-100)$, with test samples selected and randomly stratified within the ISA using a $3 \times 3$ pixel window. The impervious layer was mapped using visual interpretation, thus permitting the calculation of ISA proportion, based on the ground verified truth-value associated with the impervious layer. Verification results indicated an urban land cover classification accuracy of $94 \%$ and ISA information extraction mean relative error of 
0.64\%. Accordingly, requirements relating to comparative analysis of the spatio-temporal characteristics of urban space and land cover were deemed to be appropriately satisfied (Kuang et al., 2013).

\section{Results and analyses}

\subsection{Analysis of the structural characteristics of urban land cover in China and the USA}

Chinese urban land cover consisted primarily of ISA and other types (cropland, bare land, etc.) with a significantly smaller proportion of vegetation. ISA has exhibited a rapidly increasing trend while other land cover types have decreased (Figure 3). The proportion of ISA within Chinese cities in 2010 (69.48\%) was approximately four times that observed in 1978 (16.74\%) (Figure 4). Other land cover types have displayed a concurrently decreasing trend from almost $60 \%$ in 1978 to $14.05 \%$ in 2010 . Proportion of vegetation decreased from $18.10 \%$ in 1990 to $14.70 \%$ in 2010 . Urban land cover among USA cities primarily consisted of ISA and vegetation. The proportion of ISA displayed a gradual increase over the study period, while no significant chance was found with respect to urban vegetation (Figure 3). Results indicate that ISA increased only slightly from 1978 to 1990, with a stable growth rate developing from 55\% to 57\% after 1990 (Figure 4). The proportion of vegetation was approximately 33\% throughout the study period (Figure 4).

Trends pertaining to land cover structure within the three major Chinese cities were broadly similar with each other over the duration of the period examined. The proportion of ISA was the highest in Beijing throughout the study period, while the overall range of ISA proportion was seen to vary significantly in Guangzhou. During the period 1978-2010, the proportion of land converted to ISA was $65 \%$ in Guangzhou and $40 \%-45 \%$ in both Beijing and Shanghai. The overall proportion of vegetation in Guangzhou was the lowest throughout the study period. Quantifiable water changes were not observed during the study period in any of the six study cities.

Land cover structure within the three major USA cities changed only with regard to internal structure. ISA in Chicago increased by $13.4 \%$ over the study period, with increases of $>5 \%$ in both New York and Los Angeles. Vegetation coverage accounted for more than one quarter of land cover in the three USA cities, with no clear variation noted in terms of vegetation proportion. Other land types were characterized by a decreasing trend. This was most evident in Chicago, where 'other' land type proportion decreased from $24.33 \%$ in 1978 to $7.55 \%$ in 2010 .

\subsection{Analysis of intra-urban land changes in the major cities of China and USA}

Results suggest that the structure of intra-urban land cover in Chinese cities has changed rapidly, particularly in terms of the expansion of urban ISA in concurrence with and the decrease of other type lands since 2000. Intra-urban land cover structure in USA cities has changed gradually, with the most significant expansion of ISA occurring during the period 1978-1990. However, little change has occurred since 2000. Changes pertaining to overall ISA magnitude in the three Chinese cities $\left(61.98 \mathrm{~km}^{2} \cdot \mathrm{a}^{-1}\right)$ were 3.14 times those noted in USA cities $\left(19.72 \mathrm{~km}^{2} \cdot \mathrm{a}^{-1}\right)$ (Table 1$)$. 

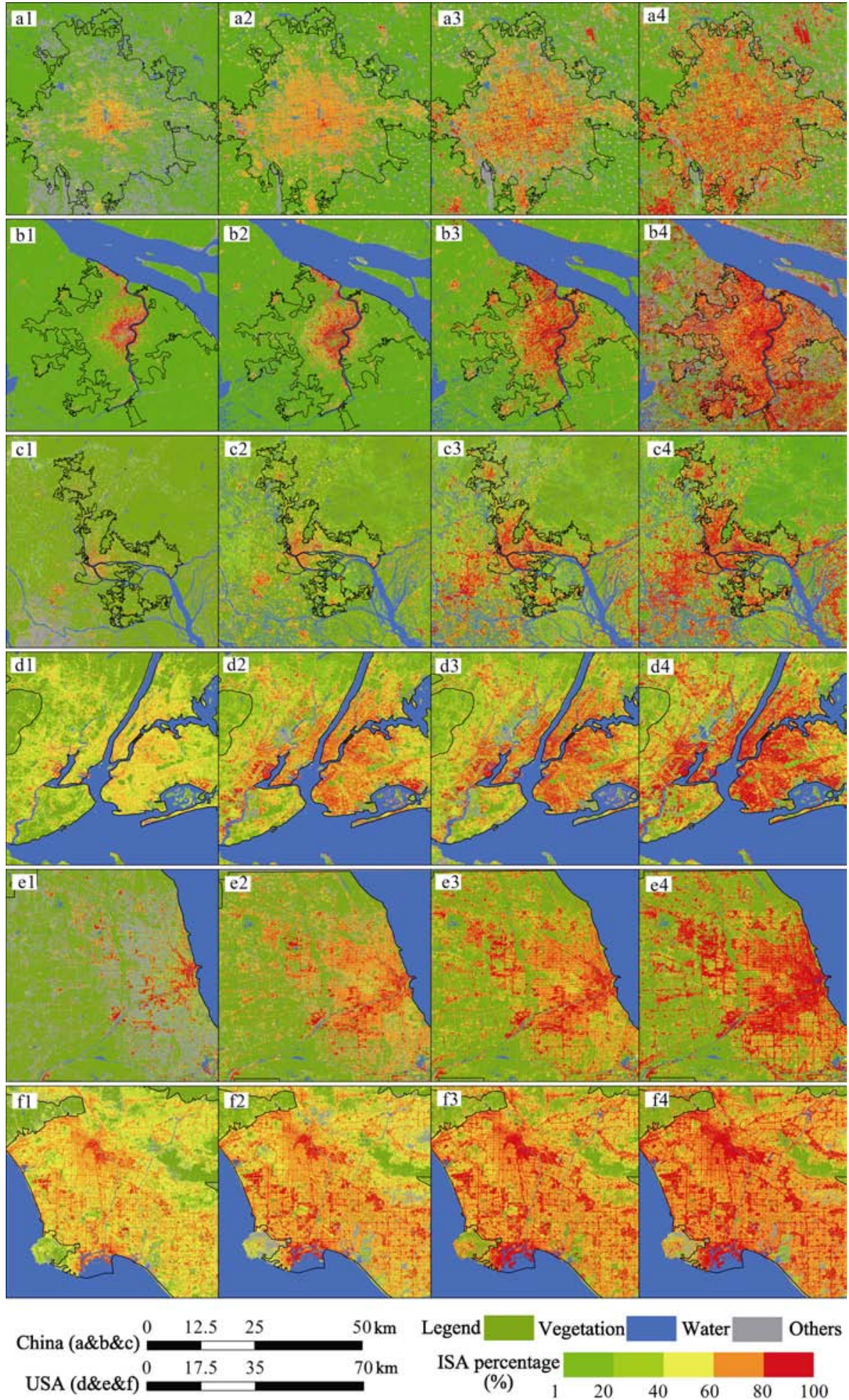

Figure 3 Spatial patterns of intra-urban land cover in the cities of China and USA from 1978 to 2010 (a, b, c, d, e and f represent Beijing, Shanghai, Guangzhou, New York, Chicago and Los Angeles, respectively; a1, a2, a3 and a4 represent intra-urban land cover from 1978, 1990, 2000 and 2010, respectively) 

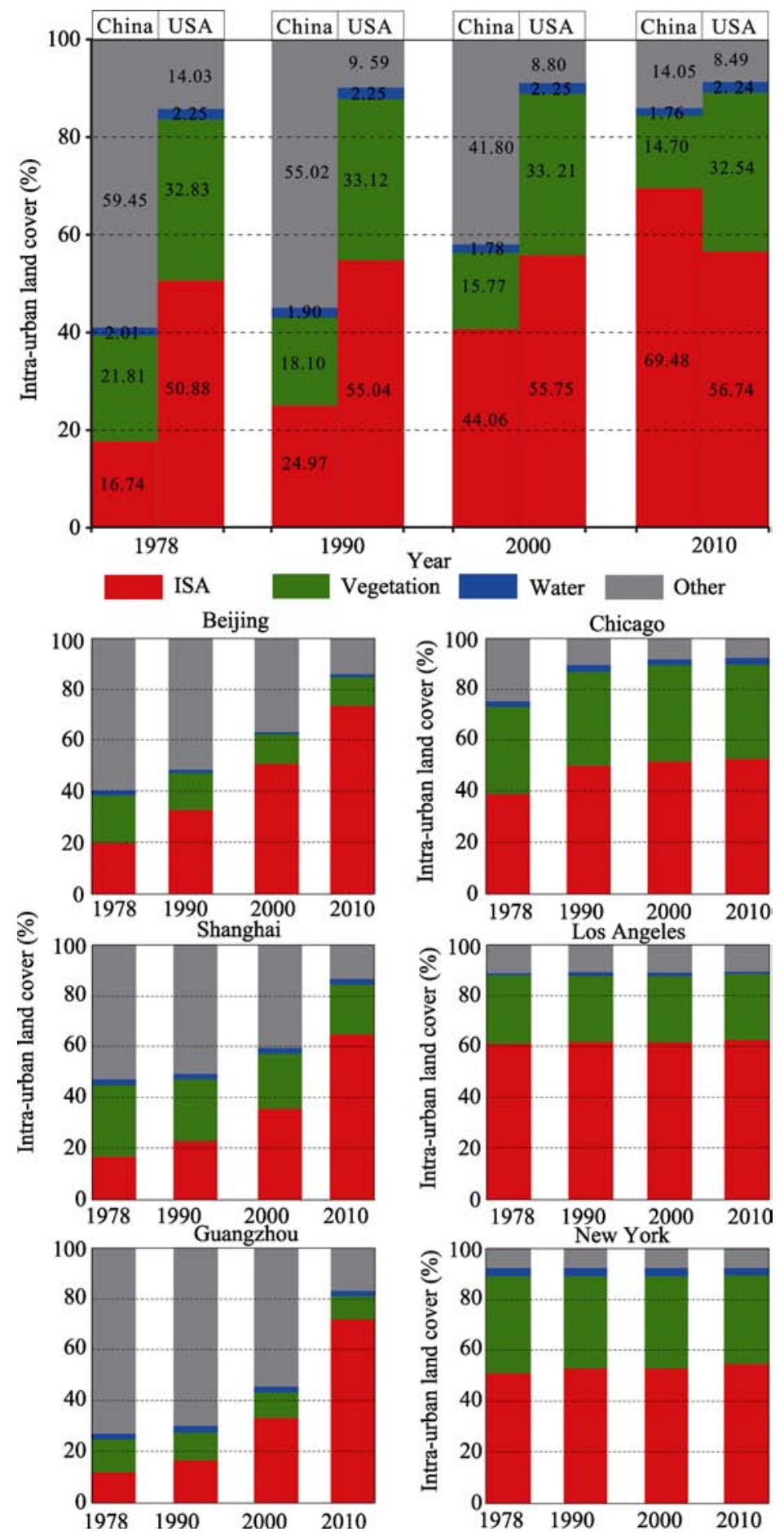

Figure 4 Percentage of intra-urban land cover in the cities of China and USA from 1978 to 2010

Development of the three major Chinese cities took place based on a 'pie'-style method, where by dispersion rapidly occurred from the city center to the periphery via a compact distribution pattern. The dominant pattern of ISA expansion is the occupation of other lands 
Table 1 Changes in intra-urban land cover within Chinese and USA study cities from 1978 to $2010\left(\mathrm{~km}^{2}\right)$

\begin{tabular}{|c|c|c|c|c|c|c|c|c|}
\hline \multirow{2}{*}{$\begin{array}{c}\text { Intra-urban } \\
\text { land cover } \\
\text { types }\end{array}$} & \multicolumn{2}{|c|}{ 1978-1990 } & \multicolumn{2}{|c|}{ 1990-2000 } & \multicolumn{2}{|c|}{ 2000-2010 } & \multicolumn{2}{|c|}{ 1978-2010 } \\
\hline & $\Delta \mathrm{S}$ & $\Delta \mathrm{S}^{\prime}$ & $\Delta \mathrm{S}$ & $\Delta \mathrm{S}^{\prime}$ & $\Delta \mathrm{S}$ & $\Delta S^{\prime}$ & $\Delta \mathrm{S}$ & $\Delta S^{\prime}$ \\
\hline \multicolumn{9}{|l|}{ China } \\
\hline ISA & 309.68 & 25.81 & 589.85 & 58.98 & 1083.98 & 108.40 & 1983.51 & 61.98 \\
\hline Vegetation & -139.53 & -11.63 & -87.80 & -8.78 & -40.10 & -4.01 & -267.43 & -8.36 \\
\hline Water & -3.90 & -0.33 & -4.63 & -0.46 & -0.55 & -0.05 & -9.08 & -0.28 \\
\hline Others & -166.24 & -13.85 & -497.42 & -49.74 & -1043.34 & -104.33 & -1707.00 & -53.34 \\
\hline \multicolumn{9}{|l|}{ USA } \\
\hline ISA & 447.87 & 37.32 & 76.48 & 7.65 & 106.76 & 10.68 & 631.12 & 19.72 \\
\hline Vegetation & 31.45 & 2.62 & 8.91 & 0.89 & -72.34 & -7.23 & -31.98 & -1.00 \\
\hline Water & -0.73 & -0.06 & -0.14 & -0.01 & -0.43 & -0.04 & -1.30 & -0.04 \\
\hline Others & -478.60 & -39.88 & -85.26 & -8.53 & -33.99 & -3.40 & -597.84 & -18.68 \\
\hline \multicolumn{9}{|l|}{ Beijing } \\
\hline ISA & 169.17 & 14.10 & 236.97 & 23.70 & 293.11 & 29.31 & 699.24 & 21.85 \\
\hline Vegetation & -60.00 & -5.00 & -32.36 & -3.24 & -5.26 & -0.53 & -97.62 & -3.05 \\
\hline Water & -3.47 & -0.29 & -3.19 & -0.32 & -0.46 & -0.05 & -7.11 & -0.22 \\
\hline Others & -105.70 & -8.81 & -201.41 & -20.14 & -287.39 & -28.74 & -594.51 & -18.58 \\
\hline \multicolumn{9}{|l|}{ Guangzhou } \\
\hline ISA & 37.88 & 3.16 & 132.92 & 13.29 & 307.92 & 30.79 & 478.72 & 14.96 \\
\hline Vegetation & -15.19 & -1.27 & -8.90 & -0.89 & -5.13 & -0.51 & -29.22 & -0.91 \\
\hline Water & -0.42 & -0.03 & -0.80 & -0.08 & -0.05 & 0.00 & -1.27 & -0.04 \\
\hline Others & -22.27 & -1.86 & -123.22 & -12.32 & -302.74 & -30.27 & -448.23 & -14.01 \\
\hline \multicolumn{9}{|l|}{ Shanghai } \\
\hline ISA & 102.63 & 8.55 & 219.96 & 22.00 & 482.96 & 48.30 & 805.55 & 25.17 \\
\hline Vegetation & -64.34 & -5.36 & -46.54 & -4.65 & -29.71 & -2.97 & -140.58 & -4.39 \\
\hline Water & -0.02 & 0.00 & -0.64 & -0.06 & -0.04 & 0.00 & -0.70 & -0.02 \\
\hline Others & -38.27 & -3.19 & -172.78 & -17.28 & -453.21 & -45.32 & -664.26 & -20.76 \\
\hline \multicolumn{9}{|l|}{ Chicago } \\
\hline ISA & 359.53 & 29.96 & 61.25 & 6.13 & 28.68 & 2.87 & 449.47 & 14.05 \\
\hline Vegetation & 120.08 & 10.01 & 15.81 & 1.58 & -20.11 & -2.01 & 115.78 & 3.62 \\
\hline Water & -1.92 & -0.16 & -0.01 & 0.00 & -0.13 & -0.01 & -2.06 & -0.06 \\
\hline Others & -477.69 & -39.81 & -77.05 & -7.71 & -8.44 & -0.84 & -563.19 & -17.60 \\
\hline \multicolumn{9}{|l|}{ Los Angeles } \\
\hline ISA & 31.21 & 2.60 & 6.39 & 0.64 & 19.36 & 1.94 & 56.97 & 1.78 \\
\hline Vegetation & -21.35 & -1.78 & -9.36 & -0.94 & 4.80 & 0.48 & -25.91 & -0.81 \\
\hline Water & 1.28 & 0.11 & -0.21 & -0.02 & -0.22 & -0.02 & 0.85 & 0.03 \\
\hline Others & -11.14 & -0.93 & 3.17 & 0.32 & -23.94 & -2.39 & -31.90 & -1.00 \\
\hline \multicolumn{9}{|l|}{ New York } \\
\hline ISA & 57.13 & 4.76 & 8.84 & 0.88 & 58.72 & 5.87 & 124.69 & 3.90 \\
\hline Vegetation & -67.28 & -5.61 & 2.45 & 0.25 & -57.03 & -5.70 & -121.85 & -3.81 \\
\hline Water & -0.08 & -0.01 & 0.08 & 0.01 & -0.08 & -0.01 & -0.08 & 0.00 \\
\hline Others & 10.24 & 0.85 & -11.38 & -1.14 & -1.61 & -0.16 & -2.75 & -0.09 \\
\hline
\end{tabular}

Note: Changes in intra-urban land cover $\Delta S$ and the annual change $\Delta S^{\prime}$ represent changes in number (positive number represent increasing area, '-’ represents decreasing area) 
cropland) which decreased at a rate of $53.34 \mathrm{~km}^{2} \cdot \mathrm{a}^{-1}$ during the overarching study period. Conversely, the overall pattern of urban development in the USA is stable and loose, with ISA expansion typically occurring at a steady pace in available space; ISA growth was primarily dominated in the USA by internal fillings.

The ISA growth rates within the three Chinese cities have increased significantly over the study period, and particularly so from 2000 to 2010 (Beijing, $21.85 \mathrm{~km}^{2} \cdot \mathrm{a}^{-1}$; Shanghai, 25.17 $\mathrm{km}^{2} \cdot \mathrm{a}^{-1}$; Guangzhou, $14.96 \mathrm{~km}^{2} \cdot \mathrm{a}^{-1}$ ). Conversely, all other land types and vegetation coverage have exhibited decreasing trends in the Chinese cities. Other land types decreased by $20.76 \mathrm{~km}^{2} \cdot \mathrm{a}^{-1}, 18.58 \mathrm{~km}^{2} \cdot \mathrm{a}^{-1}$ and $14.01 \mathrm{~km}^{2} \cdot \mathrm{a}^{-1}$, in Shanghai, Beijing and Guangzhou, respectively. While vegetation coverage decreased at rates of $4.39 \mathrm{~km}^{2} \cdot \mathrm{a}^{-1}, 3.05 \mathrm{~km}^{2} \cdot \mathrm{a}^{-1}$ and $0.91 \mathrm{~km}^{2} \cdot \mathrm{a}^{-1}$ in Shanghai, Beijing and Guangzhou, respectively, water area changes during study periods were insignificant (Table 1 ).

ISA coverage in the three major USA cities increased gradually over the almost three decade study period (Chicago, $14.05 \mathrm{~km}^{2} \cdot \mathrm{a}^{-1}$; New York, $3.90 \mathrm{~km}^{2} \cdot \mathrm{a}^{-1}$; and Los Angeles 1.78 $\mathrm{km}^{2} \cdot \mathrm{a}^{-1}$ ). Other land types in the USA cities exhibited gradually decreasing trends. Vegetation coverage in Chicago increased during the period 1978-2010, followed by a gradual decrease from 2000 to 2010; an overall increase of $3.62 \mathrm{~km}^{2} \cdot \mathrm{a}^{-1}$ was recorded. Vegetation coverage in Los Angeles showed a decreasing trend initially, followed by an increase in level of coverage; a mean rate of decrease of $0.81 \mathrm{~km}^{2} \cdot \mathrm{a}^{-1}$ occurred overall during the total study period. Vegetation coverage in New York was found to decrease during the initial study period, followed by an increase and a subsequent decrease during the last study phase; over the entire study duration, it decreased at a rate of $3.81 \mathrm{~km}^{2} \cdot \mathrm{a}^{-1}$. Water area changes during the overarching study duration were insignificant among all the three USA cities.

\subsection{Land cover characteristics in different functional districts of Chinese and USA cities}

The structure and composition of urban land cover are largely determined by the structure of urban functional areas; varying urban land cover structures are present from city to city. Land cover structure in different functional areas under varying regimes were analyzed in the current study. According to the land rent theory, land prices are inversely proportional to distance from the city center, based upon which, buildings in central areas are typically characterized by high-density development and high-height structure, with both density and height decreasing towards the urban periphery. ISA is additionally related to development density and thus represents a significant component of land cover structure, resulting in its being considered an appropriate indicator of urban building. ISA density has been shown to decrease gradually from the urban center to the periphery, albeit not at a constant or linear rate within a specific region, due to the inherent uncertainty associated with impervious layer distribution. Land cover structures have developed various functional urban areas due to anthropogenic activities and land price concentration. Based upon identified land cover structures within the six study cities, urban functional areas were selected as the research target for the analysis of land cover structure in functional city areas under different regimes. In order to quantitatively distinguish the structural differences between Chinese and USA cities due to functional area diversity, the proportion of impervious layer and green space in functional areas, i.e. central business areas, residential areas and industrial areas, were quantified from the sample points $(1 \mathrm{~km} \times 1 \mathrm{~km})$ value (Table 2$)$. 
Table 2 Sampling sites from typical functional areas within the six study cities from China and the USA

\begin{tabular}{|c|c|c|c|}
\hline Function areas & City & Central coordinate (LAT/LON, degree) & District \\
\hline \multirow{6}{*}{ Business } & Beijing & 116.462/39.909 & China World Trade Center Area \\
\hline & Shanghai & 121.438/31.195 & Xujiahui region \\
\hline & Guangzhou & $113.321 / 23.120$ & Zhujiang New City \\
\hline & New York & $-73.984 / 40.746$ & Manhattan \\
\hline & Chicago & $-87.636 / 41.879$ & Sears Tower \\
\hline & Los Angeles & $-118.149 / 34.147$ & Old Town Pasadena \\
\hline \multirow{6}{*}{ Residential } & Beijing & $116.328 / 40.061$ & Huilongguan \\
\hline & Shanghai & $121.379 / 31.112$ & Minhang District \\
\hline & Guangzhou & $113.322 / 22.968$ & Qifuxin Country \\
\hline & Los Angeles & $-118.106 / 34.094$ & San Gabriel \\
\hline & New York & $-73.951 / 40.626$ & Centralized living area \\
\hline & Chicago & $-87.754 / 41.930$ & Greenwich Village \\
\hline \multirow{6}{*}{ Industrial } & Beijing & $116.461 / 39.810$ & $\begin{array}{llll}\text { Yizhuang Star Light } & \text { Industrial } \\
\text { Park }\end{array}$ \\
\hline & Shanghai & $121.620 / 31.262$ & Jinlingjinqiao Industrial Park \\
\hline & Guangzhou & $113.522 / 23.137$ & Luogangyunbu industrial zone \\
\hline & Chicago & $-87.630 / 41.884$ & Chicago Loop Area \\
\hline & New York & $-73.970 / 40.697$ & Brooklyn \\
\hline & Los Angeles & $-118.165 / 34.045$ & Seattle South Industrial Zone \\
\hline
\end{tabular}

Central business areas, residential areas and suburban pattern in USA cities exhibited high, medium and low density impervious layers, respectively. No explicitly high or low density ISA were evident within the internal structures of the three major Chinese cities, primarily due to compact city layouts and the presence of mixed cross-functional areas. High or low densities of ISA were noted in urban fringe sand suburban areas.

The central business district (CBD) is typically located in the city center or the heart of the district and represents the primary commercial area of activity, including commercial outlets, shopping malls, governmental and public institutions, in addition to recreational and cultural facilities. Further, it is frequently characterized by convenient transport networks, including highways, railways and ports, resulting in a high building density. A high density ISA was associated with the CBD of the six study cities $(\approx 80 \%)$; the ISA density of the three major Chinese cities was somewhat higher than that of USA cities, however, the ISA density variation between Chinese and USA cities with respect to inner city districts was not significantly different (Table 3). The greenbelt area ratios in China and the USA were all $<10 \%$ with the exception of New York and Chicago.

Generally, residential areas are characterized by large populations and spatial extent, in addition to the presence of residential buildings, public buildings, green lands, roads and other engineered facilities. The public green vegetation within residential areas contributes to a higher ratio of green space than that observed within the CBD. Accordingly, a greater difference of ISA ratio and green space ratio are encountered within the internal structure of Sino-USA urban residential areas. The three major USA cities are in possession of distinct residential areas, typified by elevated levels of public vegetation. Due to rapid urbanization and concurrent population growth, Chinese cities have developed via clusters of residential 
areas embedded with commercial or industrial areas owing to previous structure and functionality. High building density in parallel with low vegetation density has occurred in residential areas with limited public green areas. Residential areas in the three Chinese cities were characterized by mean ISA proportions of $>65 \%$, while vegetation proportions were low (e.g. $11 \%$ in Shanghai). Conversely, the mean ratio of ISA to green space in residential areas of the three major USA cities was 5:3, in concurrence with a high proportion of vegetation covered lands.

Industrial areas are typically equipped with myriad construction facilities including workshops, warehouses, roads, docks and various green facilities for pollution-reduction and waste discharge. Ordinarily, industrial regions are epitomized by a high density of ISA and a low level of green coverage. As shown in Table 3 and Figure 5, the ratios of green coverage

Table 3 Percentages of ISA and vegetation within dominant functional areas in Chinese and USA cities, 2010

\begin{tabular}{cccccccc}
\hline Function areas & Cover type & Shanghai & Beijing & Guangzhou & New York & Los Angeles & Chicago \\
\hline \multirow{2}{*}{ Business } & ISA & 0.83 & 0.83 & 0.81 & 0.78 & 0.78 & 0.76 \\
& Vegetat. & 0.08 & 0.08 & 0.06 & 0.18 & 0.09 & 0.15 \\
& ISA & 0.68 & 0.65 & 0.62 & 0.45 & 0.52 & 0.56 \\
Residential & Vegetat. & 0.16 & 0.11 & 0.15 & 0.36 & 0.28 & 0.32 \\
& ISA & 0.60 & 0.63 & 0.61 & 0.76 & 0.74 & 0.72 \\
& Vegetat. & 0.07 & 0.06 & 0.05 & 0.03 & 0.02 & 0.02 \\
\hline
\end{tabular}
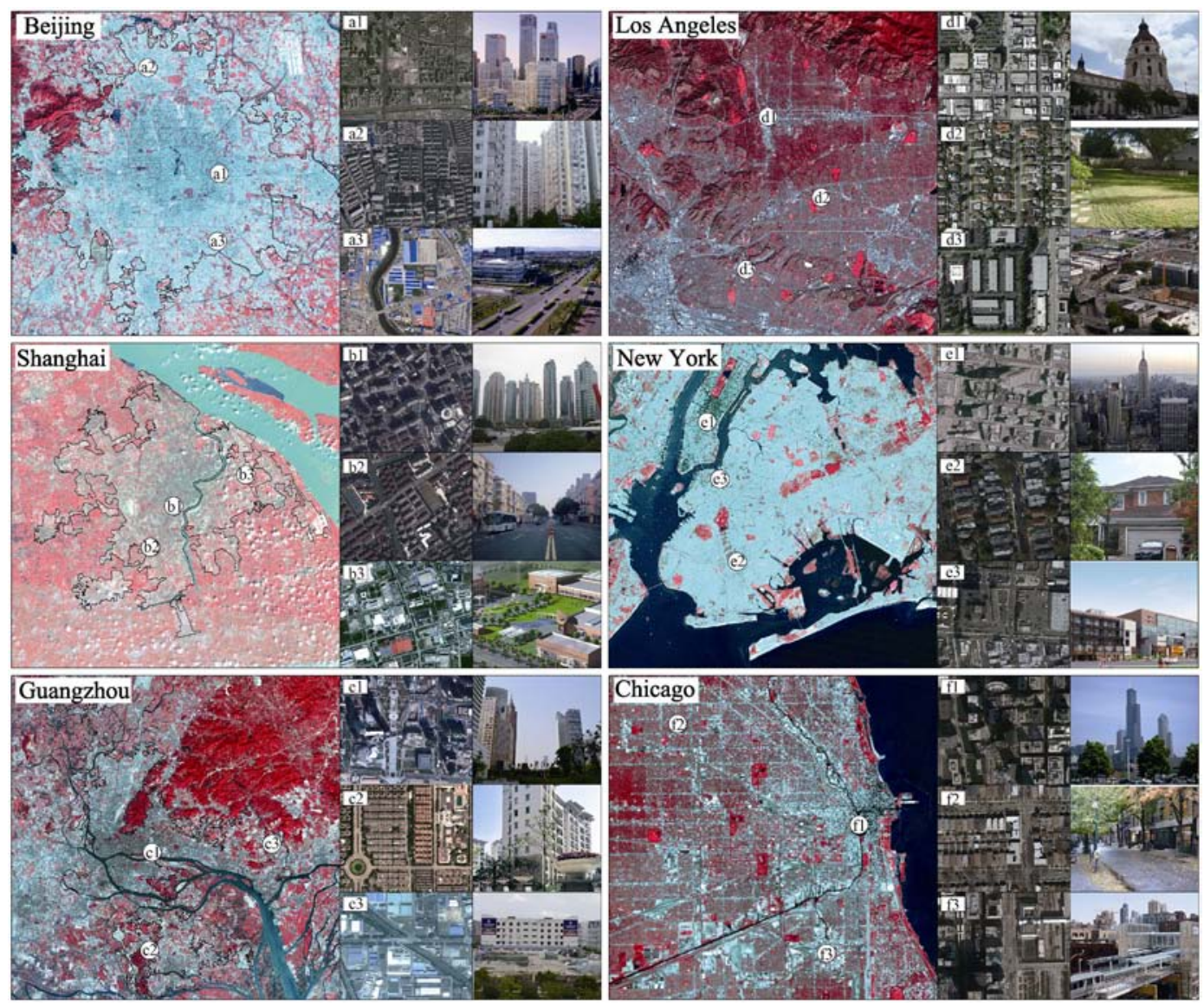

Figure 5 Image characteristics of functional areas in Chinese and USA cities under examination 
to ISA within categorically industrial areas were significantly different with respect to China and the USA. Areas characterized by bare soil and vegetation were small within USA urban industrial regions, while the proportion of ISA was significantly higher. Conversely, industrial areas in Chinese cities were associated with more green areas, and a relatively low proportion of ISA, due to necessary compliance with Chinese statutory instruments.

Data from six typical functional areas in Chinese and USA cities indicate that the proportion of ISA associated with commercial land (CBD) is high, while it was found to be relatively low in residential and industrial areas (Table 3). Analyses of ISA and vegetation data suggest that the proportion of ISA and vegetation within analogous functional areas varies significantly (Table 3). In CBD, the average ISA proportion associated with the three major Chinese cities (0.81-0.83) was higher than that of USA cities (0.76-0.78); however the proportion of vegetation was considerably lower in Chinese cities (0.06-0.08) than their USA counterparts $(0.09-0.18)$. The mean ISA proportion in residential areas of Chinese cities (0.62-0.68) was higher than that of USA cities (0.45-0.52), while green areas in USA cities displayed a significantly higher mean proportion (0.28-0.36). In categorically industrial areas, the mean proportion of ISA in the USA $(0.72-0.76)$ was higher than that of China $(0.60-0.63)$, while green areas were more frequent in Chinese industrial areas $(0.05-0.07)$.

\section{Discussion and conclusions}

\subsection{Discussion}

Differences with respect to national conditions in China and the USA have led to varying levels of policy execution within the urban planning process. Urban planning in the USA is most frequently undertaken by the local government, as dictated by federal and state governments. The urban planning model in the USA is characteristically low-density and vehicle-oriented, with urban expansion typically progressing in a 'pie-style'. Conversely, the most direct government driven means of guiding and regulating urban construction in China is through the implementation of the master planning outline; this determines the overarching position and objectives of a city via quantitative means. During the 1990s, urban extension of Chinese cities was extremely concentrated. The ISA proportion of Chinese cities was policy driven, particularly with respect to urban planning processes. The ISA proportions associated with Beijing, Shanghai and Guangzhou are primarily influenced by the traditional Chinese ideal surrounding urban planning, i.e. expansion largely proceeds from the old town center to the periphery, displaying a 'pie' trend and compact overall distribution. Urban planning in other nations has been largely influenced by so-called 'garden city' planning, developing through a decentralized layout with ISA tending to be less concentrated. Moreover, the expansion of Chinese urban ISA has also been significantly affected by policy reform, particularly those focusing on economic enhancement. The three major cities in China have undergone rapid proportional ISA growth since 1978. In concurrence with the aforementioned acceleration of urbanization, it is predicted that population growth will represent the primary driver underlying increased urban land demands. Therefore, as a central urban land use type, urban ISA will be likely affected by growing urban populations.

Economic factors are considered to be the primary causative factors with respect to the spatial expansion of ISA. According to the land rent theory, economic development is ex- 
tremely sensitive to market land supply, thus, the price of urban land gradually decreases from the center to the periphery. Accordingly, rent differentiation and associated economic leverage tends to result in the less expensive periphery areas being the primary foci of spatial development for ISA. The level of ISA growth is also significantly affected by the phase and magnitude of economic development. China is a developing country; regional economies typically reflect this. Economic development stimulates and accelerates urbanization, leading to rapid expansion of ISA in 'non-central' metropolitan areas. America is a developed country with a high level economy, whereby the urbanization process has slowed or discontinued, leading to an economy which is less responsive to economic factors.

\subsection{Conclusions}

Based on analyses of differing urban land cover structures in selected Chinese and USA cities, this study highlights different land cover structures with respect to different economic regimes, with China and the USA employed to represent developing and developed nations, respectively. This study presents analyses of the dynamic patterns of ISA expansion in six major cities from China $(n=3)$ and USA $(n=3)$ across a study period of almost 30 years. Chinese three major cities have grown rapidly in the three-decade period; continuously expanding urban space was reflected via rapid urbanization. Conversely, ISA in the three USA cities under examination exhibited a slow rate of urbanization over the past 30 years, with an 'inside fill' pattern of expansion exhibited in the USA, while rapid compact development characterized this process in China. The vegetated land surface proportion within the three USA study cities was found to be 2.21 times that of the three Chinese cities.

The land cover structure associated with Chinese cities was found to have changed significantly since 2000, with urban expansion and other land decreases accounting for the primary structural change categories. Structural change within the USA cities in this study displayed a peak during the period 1978 to 1990. Over the study period, the calculated growth rate in ISA within the three Chinese cities is approximately 3.14 times that of the three USA cities. Shanghai and Beijing have exhibited the highest levels of ISA growth during this period. ISA growth in the USA was characterized by a slow increase, with the most rapid development found to occur in Chicago. All cities exhibited an overall reduction in the proportion of other land type components, with a sharper decrease noted with respect to Chinese cities.

The overall ISA density associated with Chinese three major cities is elevated within the urban center, decreasing to a moderate or low level at the city periphery, resulting in an observed radial change pattern. This high-low-density distinction in China was found to occur in the urban fringes. ISA density in USA cities was concurrent with zone functionality and typically characterized as high-density in central business areas, medium density in residential areas, and low-density in suburban areas.

\section{References}

Alberti M, 2010. Maintaining ecological integrity and sustaining ecosystem function in urban areas. Current Opinion in Environmental Sustainability, 2(3): 178-184.

Arnold C L, Gibbons C J, 1996. Impervious surface coverage: The emergence of a key environmental indicator. Journal of the American Planning Association, 62(2): 243-258.

Ashie Y, Ca VT, Asaeda T, 1999. Development of a numerical model for the evaluation of the urban thermal environment. Journal of Wind Engineering and Industrial Aerodynamics, 81: 181-196. 
Byomkesh T, Nakagoshi N. DewanA M, 2012. Urbanization and green space dynamics in greater Dhaka, Bangladesh. Landscape and Ecological Engineering, 8(1): 45-58.

Cao X, Onishi A, Chen J et al., 2010. Quantifying the cool island intensity of urban parks using ASTER and IKONOS data. Landscape and Urban Planning, 96: 224-231.

Goldbach A, Kuttler W, 2012. Quantification of turbulent heat fluxes for adaptation strategies within urban planning. International Journal of Climatology, 33(1): 143-159.

Grimm N B, Faeth S H, Golubiewski N B et al., 2008.Global change and the ecology of cities. Science, 319(5864): 756-760.

Grimmond C, Blackett M, Best M et al., 2010. The international urban energy balance models comparison project: First results from phase 1. Journal of Applied Meteorology and Climatology, 49(6): 1268-1292.

Kuang W H, 2011. Simulating dynamic urban expansion at regional scale in Beijing-Tianjin-Tangshan Metropolitan Area. Journal of Geographical Sciences, 21(2): 317-330.

Kuang W H, 2012a. Evaluating impervious surface growth and its impacts on water environment in Beijing-Tianjin-Tangshan Metropolitan Area. Journal of Geographical Sciences, 22(3): 535-547.

Kuang W H, 2012b. Spatio-temporal patterns of intra-urban land use change in Beijing, China between 1984 and 2008. Chinese Geographical Science, 22(2): 210-220.

Kuang W H, Liu J Y, Zhang Z X et al., 2013. Spatiotemporal dynamics of impervious surface areas across China during the early 21st century. Chinese Science Bulletin, 58(14): 1691-1701.

Kuang W H, Zhang S W, Liu J Y et al., 2010. Methodology for classifying and detecting intra-urban land use change: A case study of Changchun city during the last 100 years. Journal of Remote Sensing, 14(2): 345-355. (in Chinese)

Laaidi K, Zeghnoun A, Dousset B et al., 2012. The impact of heat islands on mortality in Paris during the August 2003 heat wave. Environment Health Perspectives, 120(2): 254-259.

Lu D, Moran E, Hetrick S, 2011. Detection of impervious surface change with multi-temporal Landsat images in an urban-rural frontier. ISPRS Journal of Photogramm. Remote Sensing, 66(3): 298-306.

McGranahan G, Balk D, Anderson B, 2007. The rising tide: Assessing the risks of climate change and human settlements in low elevation coastal zones. Environment and Urbanization, 19(1): 17-37.

Millennium Ecosystem Assessment (MEA), 2003. Ecosystems and Human Wellbeing: A Framework for Assessment. Washington, DC: Island Press.

Nowak D J, Dwyer J F, 2007. Understanding the benefits and costs of urban forest ecosystems. In: Kuser J (ed.), Urban and Community Forestry in the Northeast. New York: Springer Science and Business Media, 25-46.

Nowak D J, Greenfield E J, 2012. Tree and impervious cover in the United States. Landscape and Urban Planning, 107(1): 21-30.

Oke T R, 1982. The energetic basis of the urban heat island. Quarterly Journal of the Royal Meteorological Society, 108(455): 1-24.

Potchter O, Cohen P, Bitan et al., 2006. Climatic behavior of various urban parks during hot and humid summer in the Mediterranean city of Tel Aviv, Israel. International Journal of Climatology, 26(12): 1695-1711.

Seto K C, Guneralp B, Hutyra L R, 2012. Global forecasts of urban expansion to 2030 and direct impacts on biodiversity and carbon pools. PNAS, 109(40): 16083-16088.

Sexton J O, Song X-P, Huang C et al., 2013. Urban growth of the Washington, D.C.-Baltimore, MD metropolitan region from 1984 to 2010 by annual, Landsat-based estimates of impervious cover. Remote Sensing of Environment, 129: 42-53.

Steve M Racitia, Lucy R Hutyra, Adrien C Finzi, 2012. Depleted soil carbon and nitrogen pools beneath impervious surfaces. Environmental Pollution, 164: 248-251.

Tong X, Lin C, Lu W et al., 2005. Environmental impacts of surface mining on mined lands, affected streams and agricultural lands in the Dabaoshan Mine region, southern china. Journal of Land Degradation \& Development, 16(5): 463-474.

UNDESA (United Nations Department of Economic and Social Affairs), 2012. Population Ageing and Development.

Van De Voorde T, Jacquet W, Canters F, 2011. Mapping form and function in urban areas: An approach based on urban metrics and continuous impervious surface data. Landscape and Urban Planning, 102(3): $143-155$.

Wang X X, Zhu Q J, Chen S H et al., 2007. Analysis of water, heat and $\mathrm{CO}_{2}$ fluxes on urban green space. Acta Ecologica Sinica, 27(8): 3232-3239. (in Chinese)

Wolf K M, 2003. Public response to the urban forest in inner-city business districts. Journal of Arboriculture, 29(3): 117-126.

Ying T Y, Li M , Fan W Y et al., 2010. Analysis of urban forests and heat island effect based on GIS. Journal of Northeast Forestry University, 38(8): 63-67. (in Chinese)

Yuan F, Bauer M E, 2007. Comparison of impervious surface area and normalized difference vegetation index as indicators of surface urban heat island effects in Landsat imagery. Remote Sensing of Environment, 106(3): 375-386.

Yue W Z, Xu J H, Xu L H, 2006. An analysis on eco-environment effect of urban land use based on remote sensing images. Acta Ecologica Sinica, 26(5): 1450-1460. (in Chinese)

Zhang R H, 2009. Quantity Infrared Remote Sensing Model and the Ground Experiment Base. Beijing: Science Press. (in Chinese) 